\title{
DO E-LAISSEZ-FAIRE À EDUCAÇÃO INTERMIDIÁTICA CRÍTICA*
}

\author{
Fernanda Pereira da Cunha \\ Universidade Federal de Goiás, Goiânia, GO, Brasil
}

\begin{abstract}
RESUMO: Este ensaio se propõe a discutir a utilização dos recursos digitais e suas extensões no ensino da arte nas escolas brasileiras. $O$ eixo motriz desta reflexão é discutir as diferentes possibilidades de inserção destes recursos na arte e seu ensino. Enaltecemos, assim, a necessidade de se utilizar o computador, seus inputs e outputs, como intermediadores no processo de ensino-aprendizagem da arte, em prol da educação digital crítica no ciberespaço, com o objetivo de se formar o fruidor de arte digital crítico no contexto da cultura digital.
\end{abstract}

Palavras-chave: Intermídia. Cultura digital. e-Arte-Educação. e-laissez-faire.

O ensino de arte na escola tem como premissa o desenvolvimento da capacidade crítica dos alunos para a leitura de uma expressão estética. Como explica Barbosa (1998), o desenvolvimento artístico de uma sociedade está relacionado não apenas à produção de qualidade, mas também à alta capacidade de entendimento dessa produção pelo público, capaz de decodificar corretamente a obra de arte. $\mathrm{O}$ "desenvolvimento cultural que é a alta aspiração de uma sociedade só existe com o desenvolvimento artístico neste duplo sentido" (p. 32), pois saber interpretar uma imagem está intimamente vinculado a esse crescimento cultural.

\footnotetext{
* Artigo recebido em 4/11/2013 e aprovado em 24/1/2014.
} 
Dessa maneira, a e-arte-educação é uma epistemologia da arte digital, pois intermedeia a aproximação entre o objeto de arte digital e o apreciador. A e-arte-educação torna-se facilitadora no processo de ensino-aprendizagem da arte digital.

As instituições de ensino vêm dando significativa importância à informática, que tem sido expoente de fundamental valor, por agregar a si a inserção no mercado de trabalho. Por isso, muitas escolas utilizam sofisticadas estruturas laboratoriais digitais para impressionar pais e alunos. É como se apenas a magnífica infraestrutura garantisse a plena formação da pessoa, de forma desvinculada de políticas educacionais comprometidas com seu uso. Entendemos que as escolas devem aproveitar seu arsenal supermidiático (referimo-nos à superestrutura) de tecnologias de última geração, não apenas como vitrines para garantir maior índice de matrículas, mas para formar o público consciente, como adverte Barbosa (2008, p. 111):

Com a atenção que a educação vem dando às novas tecnologias na sala de aula, torna-se necessário não só aprender a ensiná-las, inserindo-as na produção cultural dos alunos, mas também para a recepção, o entendimento e a construção de valores das artes tecnologizadas, formando um público consciente.

Faz-se necessário formar um público consciente, capaz de ler/ interpretar os códigos culturais que compõem o universo digital da sociedade em rede com autonomia e criticidade, para não ser assimilado, sugado pela "ordem de massificação humana" que tem como premissa a homogeneização. Por isso, educar somente para a produção não garante a formação plena.

Com relação ao ensino de arte e tecnologias digitais, há singular ênfase somente na produção, inserindo-se uma educação modernista digital nas escolas brasileiras, que envereda pela livre expressão - o e-laissez-faire, ou seja, uma versão eletrônica do laissez-faire. ${ }^{1}$

Em nossa vivência como professora, observamos que essa situação se repete porque o professor de arte, já modernista, transfere o modernismo convencional para o computacional ou porque quem ministra aula de artes é o professor de informática, que não tem conhecimento da matéria e de seu ensino. Resumindo, as aulas se limitam ao ensino de programas computacionais utilitários, ou têm ênfase apenas no fazer (ateliês eletrônicos), em que os alunos, que sabem mais informática que o professor, "expressam-se livremente", com a justificativa modernista de educar para o desenvolvimento emocional e afetivo. Entretanto, adverte Barbosa (1998, p. 20): 
Aqueles que defendem a arte na escola meramente para liberar a emoção devem lembrar que podemos aprender muito pouco sobre nossas emoções se não formos capazes de refletir sobre elas. Na educação, o subjetivo, a vida e a vida emocional devem progredir, mas não ao acaso. Se a arte não é tratada como um conhecimento, mas somente como um "grito da alma", não estamos oferecendo nem educação cognitiva, nem educação emocional. Wordsworth disse: "Arte tem que ver com emoção, mas não tão profundamente para nos reduzirmos a lágrimas".

Complementa, na mesma direção de crítica à "livre expressão" tal como vem sendo praticada:

A prática sozinha tem se mostrado impotente para formar o apreciador e fruidor da arte. Nos Estados Unidos, o ensino livre expressivo da arte existe nas escolas públicas, portanto para todas as classes sociais, desde os anos 30, nem por isso os americanos são apreciadores mais argutos da arte. Pelo contrário, a livre expressão, sem desenvolvimento da capacidade crítica para avaliar a produção, tem formado nos Estados Unidos um consumidor ávido e acrítico de imagens. [...] Por outro lado, é bom lembrar que o desenvolvimento da capacidade criadora, tão caro aos defensores do que se convencionou chamar livre expressão no ensino da arte, isto é, aos cultuadores do deixar fazer, também se dá no ato do entendimento, da compreensão, da decodificação das múltiplas significações de uma obra de arte. Flexibilidade, fluência, elaboração, todos estes processos mentais envolvidos na criatividade são mobilizados no ato da decodificação da obra de arte. (BARBOSA, 1991, p. 41)

A e-arte-educação pós-moderna diverge, portanto, da modernista, por não restringir o ensino da arte à produção, mas por compreender arte como expressão e cultura, com capacidade de desenvolver a cognição: "Percepção, memória, mimeses, história, política, identidade, experiência, cognição são hoje mediadas pela tecnologia" (BARBOSA, 2008, p. 111).

Buscamos, neste estudo, propor um novo (refletir sobre o) paradigma para o ensino da arte digital. O propósito é repensar o processo de ensinoaprendizagem imerso na linguagem da cultura digital, e não apenas a produção instrumentalizada com os padrões técnicos oferecidos pelos efeitos computacionais, para que o aluno se aproprie da linguagem para expressar-se.

Barbosa (2008, p. 110) indaga: "Como ver a arte produzida pelas tecnologias contemporâneas? A arte no ciberespaço estimula mais o intelecto? Qual o alcance da sensorialidade virtual?". Dada a natureza da metalinguagem no ciberespaço, as obras de arte propostas pelas novas tecnologias proporcionam uma consumação estética metassensória, estando no ciberespaço ou adaptadas a um ambiente expositivo convencional - não digital. 
Compreendemos que ver não é o termo mais adequado para a fruição da obra de arte digital, mas, vivenciar; ou, de forma metassensorial, perceber - dado que perceber converge com (re)conhecer, interpenetrando o conhecimento sensório com o cognitivo, pois as obras de arte digitais se apresentam inclusive como jogos (games), cuja apreciação só se configura de fato se o apreciador aceitar o convite interativo que a obra propõe, que exige o envolvimento de outros órgãos sensórios, não sendo mais suficiente apenas a apreciação/observação visual. Por isso, a educação estético-digital deve atender à metalinguagem e, portanto, ser intermidiática - ir para além da visual. Visão, tato, audição, olfato, paladar e o corpo como um todo se integram numa consumação estético-digital para que seja vivenciada de fato - perfazendo a metaleitura. A natureza epistemológica da apreciação estéticodigital se configura de fato num processo interacionista tecno-humano.

É, portanto, imprescindível a interação para que obra de fato aconteça. Na obra digital o fruidor é não somente o espectador, mas um personagem, um elemento da obra. Sem a sua participação, a obra não se constitui de fato, permanece uma obra em potencial.

Assim, a relação obra-apreciação apresenta uma vivência estética consumatória em outro paradigma, diferente daquele das não digitais; por isso as obras digitais se assemelham mais às instalações, embora constituídas em outra configuração, material e diálogo.

Esta característica, em que a obra de arte digital se apresenta mais com um jogo - game art -, pela sua natureza interativa programada artificialmente, vem se constituindo desde as primeiras expressões artísticas digitais. Entretanto, a ciberarte necessita de novos critérios paradigmáticos de apreciação e de conservação do mercado, da formação de críticos e das práticas dos museus.

De acordo com Lévy (1997, p. 94), a cibercultura apresenta uma diversidade de gêneros:

[...] composições automáticas de partituras ou de textos, músicas "tecno" geradas por um trabalho repetível de amostragens e de arranjos a partir de músicas já existentes, sistemas de vida artificial ou de robôs autônomos, mundos virtuais, websites voltados à intervenção estética ou cultural, hipermídias, acontecimentos possibilitados pela Rede ou implicando participação através de dispositivos numéricos, hibridizações diferentes do "real" e do "virtual", instalações interativas etc.

Essas características proliferam acentuadamente, e seu predomínio e refinamento expressivo, concomitantes ao avanço tecnológico digital, estão presentes por meio da assimilação da linguagem digital como manifestação 
cultural expressa nas artes digitais da atualidade, em que a cada período a tecnologia é mais absorvida, dando voz à poiésis digital.

O público jovem consome games de modo frenético atualmente. Os games digitais são interativos, em rede, e deles podem participar jogadores de localidades diferentes. Desenvolvem-se ambientes virtuais, que permitem vivenciar os mais diversos mundos e "concretizar" as mais diversas fantasias. $\mathrm{O}$ entretenimento concebido como game pode ser um grande deflagrador dos mais diversos consumos culturais, os quais podem capturar a mente - o desejo -, o humano. A e-arte-educação é capaz de educar o fruidor crítico digital.

A arte digital é um potencial em arte-ou melhor, uma arte em potencial -, porque só existirá como signo artístico se de fato houver a participação do intérprete. $O$ intérprete é o oxigênio pulsante da obra.

Há uma superexpectativa em torno da arte digital, no desejo de uma compreensão imediatista descolada da cultura. Um encantamento exacerbado em relação à tecnologia, ao suporte tecnológico, como se somente o instrumental bastasse como poiésis. É o que salienta Lévy (1997, p. 101):

Das artes do virtual, espera-se muitas vezes uma fascinação do tipo espetacular, uma compreensão imediata, intuitiva, sem cultura. Como se a novidade do suporte devesse anular a profundidade temporal, a espessura de sentido, a paciência da contemplação e da interpretação.

É preciso educar para formar o fruidor de arte digital crítico, repetimos. Não podemos, como educadores, aceitar arte computacional como instrumento nem tampouco aceitar que somente a apresentação do computador, seus inputs e outputs, para nossos alunos seja considerada educação inclusiva com promoção da cultura digital.

Educação não pode ser concebida como puro treinamento técnico. "Saber ver e avaliar a qualidade do que passa na tela do computador é ser crítico e atual" (BARBOSA, 2008, p. 110). Portanto, temos de formar o fruidor crítico, postulando o desenvolvimento da capacidade de ler/interpretar expressivamente a arte digital, pois a linguagem digital está imersa nos valores culturais, e a qualidade perceptiva depende, em maior escala, das significações contextuais atribuídas.

Para se educar em prol do desenvolvimento da capacidade crítica, para que nossos alunos e alunas sejam capazes de codificar e decodificar os sinais comunicacionais interligados presentes no universo digital em rede, em primeira instância, são necessárias propostas educacionais concernentes à cultura digital, que é composta por códigos peculiares. 
Há um descompasso educativo entre professores e alunos no ensino da arte digital. Enquanto os alunos consomem vorazmente o entretenimento digital, por meio de games, sites de relacionamento, Orkut, Youtube, MSN, dentre outros, os professores, em geral, utilizam a informática como instrumento, desprezando, talvez por desconhecimento, o universo cultural.

O Sistema Triangular Digital é uma proposição derivativa da Proposta Triangular.

[Essa proposta é] construtivista, interacionista, dialogal, multiculturalista e é pós-moderna por tudo isto e por articular arte como expressão e como cultura na sala de aula, sendo esta articulação o denominador comum de todas as propostas pós-modernas do ensino da arte que circulam internacionalmente na contemporaneidade. (BARBOSA, 1998, p. 41)

Assim, o Sistema Triangular Digital é uma abordagem e-arte-educativa, cujo paradigma educacional também é pós-moderno, cultural, cognitivo, contextual, interacionista e está fundamentado em três "processos mentais" que constituem sua triangulação. Esses processos se interligam por meio da linguagem digital, "para operar a rede cognitiva da aprendizagem" (BARBOSA, 1998, p. 40), ao relacionar produção artística com leitura e contextualização.

O Sistema Triangular Digital é constituído dos três componentes da Proposta Triangular que se inter-relacionam com o universo simbólico digital em questão. São eles: $e$-contextualizar, $e$-ler e $e$-fazer.

1) e-fazer: como o próprio nome expressa, trata-se de ação pela qual se pode vivenciar a execução empírica de produções artísticas intermidiáticas, através dos inputs e outputs computacionais. Ainda segundo Ana Mae Barbosa (1991, p. 34),

o fazer é indispensável para o aprendizado da arte e para o desenvolvimento do pensamento/linguagem presentacional - que, como vimos, difere do pensamento/linguagem discursivo (do discurso verbal) e também do pensamento científico lógico.

2) e-ler: na prática da leitura de produção digital, pela sua natureza, desloca-se a figura do leitor para a do intérprete, como tratamos anteriormente. Assim, essa prática desenvolve as habilidades interativas de ver, julgar e interpretar, como participador-intérprete crítico, questionador, e não meramente como ser passivo, depositário de informações transmitidas.

Assim, as áreas de crítica e estética como experiência consumatória são imprescindíveis. A leitura, que passa a se dar pelos sentidos envolvidos de acordo com interação proposta pela obra, possibilita a educação intermidiática, pois, por meio da leitura, estaremos preparando as crianças 
para a decodificação da gramática do universo computacional. Desse modo, "[nossa] ideia de leitura da imagem é construir uma metalinguagem da imagem. Não é falar sobre uma pintura, mas falar a pintura num outro discurso, às vezes silencioso, algumas vezes gráfico, e verbal somente na sua visibilidade primária (BARBOSA, 1991, p. 19).

O que se pretende é contextualizar a obra de arte digital "no tempo e explorar suas circunstâncias" (BARBOSA, 1991, p. 19). Dessa maneira, sua visualidade primária permeia todos os sentidos, não mais de um observador, mas de um elemento - o intérprete - que dá sentido à obra. Ler a imagem é vivenciá-la - consumá-la -, é entendê-la;"preparando-se para o entendimento das artes visuais, se prepara a criança para o entendimento da imagem, quer seja arte ou não" (p. 35).

3) e-contextualizar: visa ampliar os campos de sentidos das obras digitais estabelecendo comparações em diversos tempos e espaços em relação ao próprio intérprete e ao mundo que o cerca. Trata-se de parâmetro norteador para estabelecer relações, as quais podem potencializar a análise crítico-reflexiva do indivíduo, bem como a interdisciplinaridade no processo de ensino-aprendizagem, pois a "leitura dos campos de sentido da arte é o cerne de seu ensino neste início de século. A história ganha importância como contexto que dialoga com outros contextos na decodificação da obra" (BARBosa, 2008, p. 107).

A interseção entre essas três ações mentais ( $e$-fazer, $e$-ler, $e$-contextualizar) por meio da linguagem digital constitui o conhecimento da arte digital. Isoladamente, qualquer um dos elementos da tríade não corresponde à epistemologia da arte digital.

O Sistema e-Triangular, pela sua estrutura funcional sistêmica, interativa e simultânea entre todos os seus elementos constituintes, e por permitir realizar diferentes conexões (e combinações) entre os três processos mentais, é um sistema não linear e, portanto, complexo. Barbosa (1998, p. 33) salienta: “Em arte e em educação, problemas semânticos nunca são apenas semânticos, mas envolvem conceituação".

O Sistema Triangular Digital ou Sistema e-Triangular tem como objetivo o desenvolvimento crítico da percepção digital; da mente digital; do pensamento digital, em prol da fluência sensório-congnitivo-interpretativa acerca do mundo digital. Esses processos mentais, interligados, podem colocar em operação a rede cognitiva da aprendizagem da linguagem - do universo digital -, sabendo-se que cognição é (re)conhecer/perceber/conceber.

O estímulo aos processos mentais de modo metalinguístico, está no cerne epistemológico do desenvolvimento da capacidade cognitiva 
(e, portanto, perceptiva) da fluência digital crítica, que constitui o Sistema Triangular Digital.

Saber pensar e se expressar metalinguisticamente é ter fluência digital - pensamento digital -, porque o"pensamento é qualquer atividade mental ou espiritual", como concebe Descartes: "Com a palavra 'pensar' entendo tudo o que acontece em nós, de tal modo que o percebamos imediatamente por nós mesmos; por isso não só entender, querer e imaginar, mas também sentir é o mesmo que pensar", ou seja, pensar também "é discurso" (ABBAGNANo, 2000, p. 751)."É esse o pensamento que Platão chamava de dianóia, considerando-o o órgão das ciências propedêuticas (aritmética, geometria, astronomia e música), encaminhamento e preparação para o pensamento intuitivo do intelecto", no caso em questão, o intelecto digital (AbBagnano, 2000, p. 751).

O Sistema Triangular Digital está embasado, desse modo, nas ações mentais que estão imbricadas nos códigos metalinguísticos da cultura digital. A metalinguagem está intimamente introjetada em nossas sensações e percepções digitais. Essa rede cognitiva, deflagrada pelo Sistema e-Triangular, institui um processo mental sistêmico, e por isto não linear, cuja proposição depende da resposta que damos à pergunta: "Como se dá o conhecimento em arte computacional?".

O questionamento é a chave para acionar o processo cognitivo. Portanto, a proposição desse sistema se vincula à elaboração de respostas à pergunta, suscitando, por conseguinte, buscar a solução de um problema que tem como fim a produção "do material ideia". A mente comprometida com a solução de um determinado problema, submersa num ambiente simbólico, promoverá uma complexa elaboração de pensamento, na busca pela resposta significativa (ideia/signo) que responda ao problema em questão.

A ideia, sendo um produto conclusivo que comunica um sentido, que representa algo, ou ainda, sendo um material comunicativo, remete-nos mais uma vez à afirmação de Postman (1985). Segundo ele, nós não vemos a realidade como ela é, mas como são nossas linguagens - que são nossas ideias -, sendo nossas linguagens nossas mídias, nossas mídias, nossas metáforas, as quais criam o conteúdo de nossa cultura digital.

A ideia é o produto mental de algo culturalmente interpretável. Ou seja, para interpretarmos determinada ideia, necessitamos saber decodificá-la. O nível de capacidade de nossa mente para ler/interpretar códigos digitais está relacionado ao nível de imersão e interação com o universo digital e seus códigos comunicacionais. Para tanto, a epistemologia e-arte/educativa do Sistema Triangular Digital (ou Sistema e-Triangular) consiste no desenvolvi- 
mento da consciência crítica para a elaboração de critérios a serem utilizados no universo digital.

Nesse processo de ensino-aprendizagem, intenciona-se que os alunos vivenciem situações problematizadoras. A cada etapa surge um problema diferente e o aluno deverá solucioná-lo. Essas situações investigativas têm como objetivo envolver o aluno, possibilitando-Ihe uma experiência significativa, através de projetos digitais, os quais devem ter o desígnio como motivo impulsionador. Dessa maneira, a arte digital e seu ensino devem buscar transpor o modelo educativo do tipo linear, por meio das ações educativas que realizamos, visando a um modelo sistêmico do tipo sincrônico.

Entendemos por sincronismo uma abordagem e-arte-educativa constitutiva de um sistema integrador que não divide as áreas de conhecimento da arte em disciplinas. Mas que, através de ações investigativas na cibercultura, aciona processos mentais capazes de promover o desenvolvimento da capacidade de análise crítica e, portanto, de atribuir valor, além do desenvolvimento da capacidade de expressão por meio da linguagem e dos recursos digitais. Essa sincronia tem como objetivo possibilitar vivências significativas e efetivas no processo de ensino-aprendizagem digital, por promover o diálogo entre os discursos e os recursos midiáticos, e a experiência construtiva de uma expressão intermidiática.

O interessante é que parece que a escola muitas vezes deforma essa apropriação da linguagem que o jovem traz em sua bagagem cultural digital, por insistir na educação instrumental, em vez de trabalhar os valores culturais por ele agregados. A escola, ao enfatizar apenas a produção técnica digital, muitas vezes acaba por aumentar a angústia do tecnofóbico ${ }^{2}$ ou reforçar a euforia do tecnomaníaco.

Ambas as situações interferem no processo do ensino-aprendizagem de quem utiliza tais recursos: no primeiro caso, o aluno que não quer nem chegar perto da máquina; no segundo, o seu centro de interesse é quase totalmente voltado para o que a máquina faz, para desenvolver trabalhos que se restringem aos recursos que o equipamento possibilita.

O aprendiz tem, geralmente, uma receptividade curiosa em relação ao equipamento empregado. Se essa curiosidade for bem aproveitada pelo professor, poder-se-ão evitar, em muitos casos, as duas situações opostas e específicas, ambas prejudiciais, com as quais temos nos deparado em sala de aula: alunos "tecnofóbicos" e "tecnomaníacos".

Os jovens de hoje, que nasceram com a informática, transpiram a linguagem computacional da sociedade em rede, enquanto muitos professores ainda necessitam dominar o instrumento. Essa incongruência 
tem gerado uma inversão de papéis. As escolas não estão preparadas para formar fruidores da cultura digital, além de "corrigirem"- excludentemente - o repertório digital que seus alunos trazem consigo, castrando as expressões digitais, por identificá-las como erros gramaticais. Ora, a escola tem de identificar e trabalhar os valores culturais trazidos pelos alunos, mas, muitas vezes, se coloca como uma importante entidade de segregação da cultura digital.

Temos notado o quanto parece difícil identificar a geografia da cultura digital. Se as escolas aprendessem o processo de ensino-aprendizagem calcado no diálogo, na troca, na interculturalidade, teriam menos preocupação com a instrumentalização dos aparatos tecnológicos, dando ouvidos às vozes que disseminam a linguagem digital. Para ensinar, temos de aprender. Para aprender, temos de estar abertos para ouvir o que o mundo tem a dizer. "A consciência da tecnologia e da arte para a educação da recepção das artes tecnológicas é o que deveríamos procurar devolver para ver um público crítico e informado" (BARBOSA, 2008, p. 110).

Os novos meios de comunicação mediada por computador (CMC) estabelecem outro paradigma de comunicação, viabilizando a formação de comunidades virtuais, as quais compreendem "uma rede eletrônica de comunicação interativa autodefinida, organizada em torno de um interesse ou finalidade compartilhados, embora algumas vezes a própria comunicação se transforme no objetivo" (CASTELLS, 1999, p. 385). Essas comunidades virtuais vêm proliferando abruptamente em escala global, atingindo, sobretudo, os jovens.

Assim, a escola, os dirigentes de ensino e os professores necessitam aprender com os jovens a consumação estética da cultura digital, para ensinálos a ver de forma mais aguçada. Orkut, MSN, comunidades virtuais, perfis de identidades etc, devem ser incorporados tanto quanto outras manifestações/ expressões humanas. Qual é o medo? Há necessidade de formação crítica dos profissionais da escola quanto à cultura digital, e as instituições formadoras devem estar preparadas para formar o crítico digital.

A formação crítica daqueles que saíram da escola antes da revolução tecnológica e que não tiveram acesso às novas tecnologias é responsabilidade das instituições culturais. A elas compete abordar os aspectos da tecnocultura, indo além da instrução rotineira, possibilitando a reavaliação do sentido da criatividade, da percepção, da cognição, da educação. (BARBOSA, 2008, p. 111-112)

A e-arte-educação está intimamente inter-relacionada com os meios tecnológicos interligados. Estes, portanto, são seu campo de estudo episte- 
mológico. Ao simplificar, minimizar o conceito de técnica, desvinculando as relações contextuais de seu conceito, podemos estar incorrendo na banalização, bem como no reducionismo epistêmico. Com isso, corre-se o risco de o ensino enveredar para simples atividades de treinamento técnico, em que a instrumentalização passa a ser o fim, e não o meio para reverberar ações expressivas autônomas do sujeito.

Com uma educação digital questionadora, o centro de interesse deixa de ser a máquina, por se viabilizar o desejo exploratório, indócil e curioso que pode ensinar a conhecer e a expressar. Assim, o equipamento se desloca do centro das atenções e assume seu verdadeiro papel de facilitador do processo de ensino-aprendizagem da arte.

Nesse contexto, o instrumento torna-se tanto intermediador como suporte desse processo, possibilitando o desenvolvimento de um espírito crítico-questionador, "capaz de romper limites, subverter critérios e instaurar novos paradigmas", passando a permear todos os níveis "técnicos" (BARBOSA; FerRara; VernasCHI, 1993, p. 73). Concordamos com Nemer, que considera "o ensino da arte muito mais amplo, mais complexo e mais rico que o restrito treinamento visual e mecânico" (apud Barbosa; FerRara; VernasCHI, 1993, p. 73).

Devemos procurar desenvolver com nossos alunos e alunas um processo educativo centrado no indivíduo e em seu ambiente cultural e político, por meio de projetos temáticos, num "sistema de avaliação contextualizado" (GARDNER, 2000, p. 115). O objetivo é atingir procedimentos e instrumentos que sejam "justos com a inteligência", para que os estudantes se envolvam e tomem consciência de suas responsabilidades nesse processo. Isso possibilita a superação de barreiras da educação formal, bem como de sua forma padronizada de avaliação, constituindo uma postura educativa tecnoética.

O processo avaliativo, nesse panorama, não se resume a um instrumento aplicável igualmente a todos os estudantes, com o objetivo de medir conhecimentos quantitativos, e sim qualitativos. Desse modo, a avaliação tem como objetivo operar como um instrumento auxiliador no processo contínuo da realidade vivenciada pelos indivíduos, "dando-lhes a chance de refletir sobre sua experiência e sentimento em relação aos seus interesses e potencialidades" (GARDNER, 2000, p. 93). Assim, as avaliações contextualizadas "refletem uma complexidade realística; o conteúdo é dominado como meio, não como fim, e os alunos devem propor e esclarecer problemas, não apenas oferecer soluções" (p. 115).

Para proporcionar ao educando experiência artística, fundamentação teórica e reflexão, é preciso elaborar, testar e refazer propostas coletivamente. 
Algumas respostas são mais rápidas, como aprender a apresentar determinadas soluções que o novo equipamento exige; outras virão com o tempo, no posicionamento estético e crítico perante o mundo. O importante é procurar ser sujeito e não objeto da prática que desenvolvemos, juntamente com alunos e alunas, conscientes de que o trabalho é uma busca constante.

Os educandos devem lançar mão dos recursos intermidiáticos para experimentarem os limites do tempo, da improvisação técnica (intuitiva) que se interpõem ao direcionamento de um processo de ensino-aprendizagem com ênfase na expressão, por meio da intermídia/metalinguagem, recorrendo às escolhas que impulsionem o julgamento expressivo mais adequado.

Assim, as pesquisas - o processo investigatório-exploratório digital desempenham um papel singular nesse processo de ensino-aprendizagem. Elas devem estimular a vivência e contribuir com informações significativas, as quais são impossíveis de ser obtidas por meio da internet ou de outro meio digital interconectado, bem como por outra forma de registro informacional que dialoga com os meios digitais.

Os alunos e as alunas se entusiasmam ao se envolver de modo mais afetivo com o projeto, tomando para si autonomamente a responsabilidade na construção desse discurso empolgado. Notamos que o jovem, hoje, em especial os alunos de classe média e média alta da cidade de São Paulo, têm uma tendência ao sedentarismo. Assim, vê-los em ação, desejosos de levar adiante suas atividades, traz muito incentivo à nossa prática profissional.

As expressões intermidiáticas oriundas da internet, pela sua natureza de navegabilidade ou por um discurso apresentado (nos referimos aos discursos multi e intermídias, e não somente ou exclusivamente ao textual ou oral), estão intimamente relacionadas com o desenvolvimento de um roteiro intermidiático, o qual supõe uma ideia, uma intenção expressiva. Desse modo, os alunos desenvolvem uma atividade:

Transformar uma história qualquer num roteiro cinematográfico significa penetrar num universo estrito de escolhas estéticas ao nível do equilíbrio visual (cores, formas, movimentos), do efeito sonoro (graves, agudos, ritmo, volume) e da competência narrativa (encadeamentos lógicos e psicológicos, pontos de vista, jogos de tensões e reflexões etc.). (GARDNER, 2000, p. 95-96)

A partir do conteúdo ou de uma ideia, os estudantes realizam o roteiro para a expressão intermidiática, concomitantemente à edição, havendo intensa dedicação na escolha das imagens, sons e outros efeitos (processo que compõe a edição/produção), o que pode potencializar ou minimizar o discurso desejado. A relação íntima entre o fazer, o ler e o contextualizar 
mostra-se um diálogo construtivo, com vistas à realização de uma construção intermidiática, que deve estar imerso num universo de significação.

Franco (1998) faz uma distinção com relação ao cinema e ao filme: enquanto o primeiro é um universo de produção, o último é universo de significação. Portanto, a ação do fazer, nessa atividade, está vinculada à concepção de filme, o qual está contido no universo de criação: "espaço de escolhas do artista ou comunicador, campo de manifestação do sentimento, no que respeita ao fazer" (GARDNER, 2000, p. 52).

Dessa maneira, amplia-se a potencialidade ilimitada de técnicas e materiais, bem como suas combinações, permitindo experimentar todas as opções para explorar e criar novas possibilidades nesse campo, tendo apenas a imaginação como limite.

Uma das importantes situações problematizadoras que podem ser vivenciadas nessa atividade/produção criativa é a síntese. Outra é a abstração das informações e sentimentos que se deseja explorar em suas produções.

Qualquer atividade artística exige do criador a sensibilidade de perscrutar no real o jogo de emoção e racionalidade predominante no seu tempo e devolvê-lo, mediado por sua própria emoção e pelas escolhas da sua linguagem, em obras que espelhem seu público. Esse diálogo íntimo e universal de sensibilidade humana constitui o alimento da mente. Cada sociedade tem suas especiarias e seu paladar próprio, no cardápio cultural. (Franco, 1998, p. 88)

Resumindo, os alunos devem ter a oportunidade de vivenciar um processo educativo centrado no indivíduo, com um sistema de avaliação contextualizado que os preveniria contra o individualismo - e com o objetivo de atingir procedimentos e instrumentos que sejam "justos com a inteligência". É por isso que devemos propor políticas e ações educativas que promovam o envolvimento e o desenvolvimento da consciência das suas responsabilidades nesse processo.

Compreendemos que a integração escola-alunos-pais-comunidade (digital e não digital) é uma ação significativa no processo da construção da comunicação que, no mundo intermidiático, tenha como objetivo o desenvolvimento da formação do conhecimento reflexivo-crítico do aluno. Os professores de arte que eventualmente ainda rejeitam tais ferramentas contemporâneas midiáticas podem, com base no exposto, incorporá-las em seus recursos pedagógicos, como intermediadoras no processo de ensino-aprendizagem.

Os recursos tecnológicos podem estimular os alunos a inter-relacionar produção com leitura e contexto e facilitar esse processo. 
Esta integração corresponde à epistemologia da arte. O conhecimento das artes tem lugar na intersecção: experimentação, decodificação e informação. Nas artes visuais, estar apto a produzir uma imagem e ser capaz de ler uma imagem são duas habilidades inter-relacionadas. (BARBOSA, 1998, p. 17)

Esperamos, portanto, que nossa prática em sala de aula e o aprofundamento teórico proporcionado por esta pesquisa contribuam para resgatar essa inter-relação.

O ciberespaço deve ser um sistema marcado pela identidade, em que as partes formam um todo não homogeneizado, multicultural, multidialogal, multidisciplinar e assimétrico. Há de se estabelecer uma globalização (presente nas redes vivas como a internet) ecológico-ética. A ideia é dinamizar a identidade pessoal pelo (re)conhecimento das diferenças por meio de uma interatividade crítico-autônoma. Não ocorrendo isso, poderá imperar uma ditadura globalizante, hegemônica, em que o capitalismo global, não centralizado, mas com poder vertical, manipulador, acentua o analfabetismo e a homogeneização do pensamento humano. Há de se escolher entre a globalização democrática (horizontal) e a arbitrária (vertical).

Em suma, a comunicação metalinguística presente em nossas vidas integra nossas expressões escritas, orais e audiovisuais, as quais compõem a cultura digital, impondo a necessidade de os dirigentes de ensino, bem como os educadores, reavaliarem os atuais programas educacionais. Essa reavaliação também deve ocorrer nas políticas educativas e nos processos de ensino-aprendizagem, para que outros paradigmas educacionais possam ser estabelecidos, de modo convergente com as novas formas de expressão e de cultura.

\section{FROM E-LAISSEZ-FAIRE TO CRITICAL INTERMEDIA EDUCATION}

Abstract: This essay discusses the use of digital resources and their extensions in the teaching of art in Brazilian schools. The pivot of this reflection is a discussion on the different possibilities of integrating these resources in art and its teaching. It focuses on the need to use the computer and its inputs and outputs as intermediaries in the teaching/learning process of Art for the sake of a critical digital education in cyberspace, with a view to forming appreciators of critical digital art in the context of digital culture.

KEY WORDS: Intermedia. Digital culture. E-arte-educação. E-Laissez-faire. 


\section{DEL E-LAISSEZ-FAIRE A LA EDUCACIÓN INTERMEDIÁTICA CRÍTICA}

RESUMEN: Este ensayo tiene como propósito discutir la utilización de los recursos digitales y sus extensiones en la enseñanza del arte en las escuelas brasileñas. El eje motriz de esta reflexión es discutir las diferentes posibilidades de insertar estos recursos en el arte y su enseñanza. Resaltamos, de esta forma, la necesidad de utilizar el computador sus inputs y outputs como intermediadores en el proceso de enseñanza/aprendizaje del arte, en pro de la educación digital crítica en el ciberespacio, con el objetivo de formar el usuario del arte digital crítico en el contexto de la cultura digital.

Palabras Claves: Intermedia. Cultura digital. Educación Artística Digital. E-laissez-faire.

\section{NOTAS}

1. Laissez-faire é parte da expressão em língua francesa ("laissez-faire, laissez-aller, laissez-passer"), que significa literalmente "deixai fazer". É o mote do liberalismo clássico. Disponível em: http://pt.wikipedia.org/wiki/Laissez-faire. Acesso em: 10 out. 2008.

2. Os tecnofóbicos são aqueles que possuem aversão, repulsa, medo de se relacionar com o equipamento, de tal maneira que se paralisam diante dele. Em nossa prática como professora, presenciamos, dentre outros casos peculiares e particulares, o de uma aluna que nas primeiras aulas tinha a mão que estava sobre o mouse gelada, suada e endurecida, a ponto de não conseguir mover os dedos para acioná-lo. Já os tecnomaníacos são aqueles fascinados pelas possibilidades técnicas que o equipamento oferece, a tal ponto que a aula acaba e não conseguem dirigir-se a outra atividade.

3. Ou arquitetura de navegação - existem várias nomenclaturas de acordo com a natureza da produção a se desenvolver, mas essencialmente todas têm como eixo central o roteiro, ou seja, um caminho ou múltiplos caminhos que são programados.

\section{REFERÊNCIAS}

ABBAGAGNO, N. Dicionário de filosofia. São Paulo: Martins Fontes, 2000.

BARBOSA, A. M. T. B. A imagem e o ensino da arte. São Paulo: Perspectiva; Porto Alegre: Fundação lochpe, 1991.

. Tópicos e utópicos. Belo Horizonte: C/Arte, 1998.

. Arte/educação contemporânea: consonâncias internacionais. 2. ed. São Paulo: Cortez, 2008.

BARBOSA, A. M. T. B.; FERRARA, L. D. A.; VERNASCHI, E. O ensino das artes nas universidades. São Paulo: Edusp, 1993.

CASTELLS, M. A sociedade em rede: a era da informatização: economia, sociedade e cultura. 2. ed. v. 1. São Paulo: Paz e Terra, 1999. 
FRANCO, M. S. Escola audiovisual. Tese (Doutorado) - Escola de Comunicação e Artes, Universidade de São Paulo, São Paulo, 1988.

GARDNER, H. Inteligências múltiplas: a teoria na prática. Porto Alegre: Artmed, 2000.

LÉVY, P. Quatro obras típicas da cibercultura: Shaw, Fujihata, Davies. In: DOMINGUES, D. (Org.). A arte no século XXI: a humanização das tecnologias. São Paulo: Ed. Unesp, 1997.

POSTMAN, N. Amusing ourselves to death: public discourse in the age of show business. Nova York: Penguin Books, 1985.

Fernanda Pereira da Cunha é graduada em Educação Artística Licenciatura Plena pela Fundação Armando Álvares Penteado. Mestre e doutora em Artes pela USP. Professora da graduação, do Programa de Pós-Graduação Interdisciplinar em Performances Culturais, coordenadora do curso de Especialização em Arte/Educação Intermidiática Digital da EMAC/UFG. Atua principalmente nos seguintes temas: intermídia, cultura digital, e-Arte-Educação.

E-mail: fernanda.pcunha@hotmail.com 